\title{
Сорбционные процессы в почвах. Вопросы изучения и современное состояние проблемы
}

\author{
(С 2021 Горбунова Н.С., Громовик А.И., Черепухина И.В., Терентьева Ю.Ю. \\ Воронежский государственньій университет, Воронеж
}

Поступила в редакцию 02.10.2020 г.

DOI: $10.17308 /$ sorpchrom.2021.21/3360

Интерес к изучению сорбционных способностей почв, обменных катионов, сорбции и адсорбции, исследованию взаимодействий между органическими и минеральными компонентами в современной литературе связан не только с выяснением механизмов образования гумусовых веществ специфической и неспецифической природы, но и формированием почвенного поглощающего комплекса. Важность вопроса связана и с современным экологическим состоянием почв и биосферы, в связи с всевозрастающими антропогенными нагрузками. Цель: выявить основные тенденции в становлении, развитии и современном состоянии проблемы изучения сорбционных свойств почв и процессов, связанных с ними.

Задачи: исследование возникновения, становления и развития науки о поглотительной способности почв, почвенно-поглощающем комплексе, сорбционных процессах происходящих в почве, обменных и поглощенных катионах; освещение кинетики процесса; анализ современной литературы, посвященной вопросам взаимодействия ППК, глинистых минералов, органо-минеральных соединений с веществами, поступающими из вне; матричная, фрактальная и кластерная организация почв.

При современной антропогенной нагрузке и всевозрастающей интенсификации сельскохозяйственного производства, происходит усиленная распашка угодий, что приводит к сдвигу равновесия коллоидной системы в сторону коагуляции. Но, согласно последним полученным данным, пахотные почвы, выведенные из сельскохозяйственного оборота, способны к самовосстановлению, что проявляется в первую очередь в восстановлении их коллоидной системы до исходного состояния. Равновесие сдвигается в сторону пептизации. Современные представления о почвах, как коллоидно-гелевой матрице позволяют взглянуть на них как на системы, в которых почвенные свойства определяются состоянием и свойствами почвенных гелей, образованных в результате взаимодействия гумусовых веществ и минеральных наночастиц. Минералорганические компоненты, образующиеся на поверхности минеральных соединений почв и ее агрегатов с помощью адсорбции молекул органических соединений, приводят к сильной трансформации поверхности. Результатом этих процессов является специфичность и избирательность поверхности в поглощении ряда веществ.

Ключевые слова: почвенно-поглощающий комплекс, поглотительная способность почв, сорбционные свойства почв, адсорбция и сорбция, катионный обмен.

\section{Введение}

В настоящее время учение о сорбционных свойствах почв является наиболее интенсивно развивающимся разделом химии почв. Сорбционная способность является биосферной функцией почв. Академик Г.В. Добровольский подчеркивает уникальность и самостоятельность «сорбционных функций» почв.
Все элементы питания, их поведение и доступность растениям определяются сорбционными свойствами почв. Огромная удельная поверхность почвенных частиц позволяет удерживать как твердые частицы, так и коллоидные. Следует отметить сорбционные способности к соединениям находящимся в почвенном растворе. Особая актуальность данной проблемы определяется еще и современ- 
ными техногенными процессами, поскольку почва участвует в регуляции потоков практически всех загрязняющих веществ биосферы, выступает как главный компонент экосистемы.

Рассматриваемые вопросы о почвенной поглотительной способности, ее катионном обмене, а также сорбционных процессах и свойствах почв являются основными разделами химии почв. Понимание и решение данных проблем позволяет не только диагностировать химическое, физическое состояние почв, а также влиять на динамику процессов, заложенных в этих понятиях. Сорбционные процессы и свойства почв отражаются на динамике химических компонентов и определяют миграционные способности большинства элементов. С точки зрения современного экологического состояния окружающей среды важным является зависимость поведения тяжелых металлов, радионуклидов и других поллютантов от сорбционных свойств почв. Так, почвы, не обладающие высокой сорбирующей способностью не способны задерживать загрязнители, которые попадают в грунтовые и поверхностные воды, и тем самым вовлекаются в малый биологический и большой геологический круговороты. Все это определяет особое внимание к вопросу об изучении сорбционных характеристик почв.

\section{Развитие представлений о сорбционных свойствах почв}

Систематическое изучение вопроса началось в середине XIX века. Результатом исследований Томпсона и Уэя явилась формулировка основных закономерностей катионного обмена; а именно эквивалентность обмена и высокая скорость протекания реакций. Термин «обменные основания», применяемый и в настоящее время, впервые был употреблен Джонсоном. В России проблемой поглотительной способности почв начал заниматься А.Н. Сабанин, который выделил химическое, физическое и физико- химическое поглощение. Его исследования продолжил и развил К.К. Гедройц [1], он более детально исследовал физико-химическую или обменную поглотительную способность. Сформулировал понятие о почвенном поглощающем комплексе (ППК), емкости поглощения. Им установлено, что с увеличением валентности катионов возрастает их энергия поглощения; если валентность равная, то энергия поглощения увеличивается пропорционально возрастанию атомной массы. Маттсон [2] сформулировал представление о коллоидах с постоянными положительными, отрицательными и переменными зарядами, изменяющимися в зависимости от $\mathrm{pH}$ почвенного раствора. Коллоиды имеющие переменный заряд, Маттсон назвал амфолитоидами. Уравнения для расчета коэффициента селективности в реакциях бинарного обмена предложены Е.Н. Гапоном [3] и Б.П. Никольским [4].

И.Н. Антипов-Каратаев [5] в своих экспериментах доказал гетерогенность обменных позиций в образцах почв и в образцах монтмориллонитовых глин, проявляющуюся по-разному при взаимодействии с различными катионами. Результатом исследований В.А. Чернова явилось доказательство того [6], что главным элементом, определяющим обменную кислотность является $\mathrm{Al}$, а в ППК металл представлен не только катионом $\mathrm{AI}^{3+}$, но и гидроксокомплексами с разной величиной заряда. Н.П. Ремезов [7] при исследовании зональных типов почв установил, что при изменении состава обменных катионов, меняется и величина емкости катионного обмена. Гейнсом и Томасом предложено уравнение расчета коэффициента селективности. Сорбционной способностью органического вещества почв занимались И.В. Тюрин, М.М. Кононова, Л.Н. Александрова, Д.С. Орлов, Шнитцер, Стефенсон [8-12]. Сорбционной способностью глинистых минералов - Н.И. Горбунов, Э.А. Корнблюм, Б.П. Градусов, Н.П. Чижикова, Джексон [13-15]. 
В последнее время особое внимание уделяется исследованию реакций происходящих на границе раздела: твердая жидкая - газообразная фаза. Фундаментальные работы в этой области принадлежат Г. Спозито, В. Штамму [16-19]. Одним из интересных направлений в исследовании сорбционных свойств почв является изучение процессов на поверхности раздела: твердая фаза почв - почвенный раствор. Данное направление интенсивно развивается, сопровождаясь математическим моделированием данных процессов. Известны такие версии почвенно-геохимических моделей: GEOCHЕM, MINTEQ. Создание моделей помогает описать количественное участие отдельных компонентов почвенного раствора в следующих процессах: осаждения, растворения, адсорбции, десорбции и обмена. Модельные эксперименты описанных процессов отражены в работах Спозито, Спаркса, Штамма [16-21], среди отечественных исследователей - Е.В. Мироненко, Я.А. Пачепский [22].

\section{Функциональные группы на поверхности минеральных и органических почвенных компонентов}

Реакции, проходящие на поверхности твердых частиц протекают благодаря присутствию функциональных групп, которые определяют их химическую активность. Такими функциональными группами в почве являются: специфические и неспецифические органические вещества, органоминеральные соединения, тонкодисперсные слоистые силикаты, минералы оксидов и гидроксидов $\mathrm{Fe}, \mathrm{Al}$ и $\mathrm{Mn}$. На характер взаимодействия влияют кислотно-основные свойства компонентов и величины электроотрицательности химических элементов.

Глинистые минералы являются источником как постоянного, так и переменного заряда. Постоянный заряд характерен для трехслойных и четырехслойных глинистых силикатов с изоморфизмом в кристаллической решетке. Кроме того, глинистые минералы могут быть источником переменного заряда или зависимого от $\mathrm{pH}$. В данном случае заряд локализован на боковых сколах глинистых минералов в виде гидроксильных групп, способных к реакциям протонированиядепротонирования, что определяется $\mathrm{pH}$ окружающей среды. Минералы оксидов и гидроксидов Fe, Al, Mn, Si чаще всего выступают источниками переменного заряда.

Все органические соединения в почвах можно объединить в две большие группы: 1) неспецифические органические соединения и 2) специфические гуминовые вещества. Первая группа представлена поступающими в почву веществами являющимися продуктами разложения растительных и живых организмов, а также продуктами жизнедеятельности почвенных микроорганизмов и корневых систем растений. Преобладающими компонентами перечисленных продуктов являются: лигнин, полисахариды, моносахариды, алифатические и ароматические кислоты и аминоксилоты. В молекулах неспецифических органических веществ функциональными являются следующие группы: метоксильные, карбоксильные, фенольные, аминогруппы. Вторая группа - специфические гумусовые вещества - это азотсодержащие высокомолекулярные соединения представленные гуминовыми кислотами, фульвокислотами и гумином. Среди функциональных групп доминируют карбоксильные и фенольные гидроксилы, несколько в меньшей степени - карбонильные, метоксильные, аминогруппы, имидазол, спиртовые ОН-группы, сульфгидрильные SH-группы [10, 12, 23]. Сродство функциональных групп к протону определяет сорбционные свойства органического вещества почв. Так, карбоксильные группы имеют относительно низкое сродство к протону, вследствие чего они имеют отрицательный заряд и поглощают катионы, а фенольные группы, напротив, имеют высокое сродство к протону, поэтому поглощают анионы. 


\section{Строение поверхности раздела «твердая фаза» - «почвенный раствор»}

Исследования строения поверхностей раздела «твердая фаза» - «почвенный раствор» базируются на подходах теоретических концепций химии координационных соединений и принципах коллоидной химии. Несмотря на разделение, данные подходы тесно взаимосвязаны, а лучшие результаты получаются на использовании достижений обоих направлений.

Выделяются два типа поверхностных комплексов - внешнесферные и внутрисферные. Внешнесферные образуются между поверхностью сорбата и поглощаемым ионом в присутствии растворителя между ними. Растворитель препятствует развитию ковалентных связей, а ионы удерживаются слабыми электростатическими силами. Такой тип взаимодействия называют неспецифической адсорбцией. К этому же типу относят большинство реакций ионного обмена.

Внутрисферные комплексы образуются без участия растворителя, что приводит к возможности образования прочных ковалентных связей. Данные комплексы достаточно устойчивы, поскольку для их разложения необходима высокая энергия активации. Исходя из современных представлений, основанных на химии координационных соединений, все реакции, протекающие в системе твердая фаза - раствор, можно разделить на четыре группы:

1. Кислотно-основные равновесия:

$$
\begin{aligned}
& \equiv \mathrm{S}-\mathrm{OH}+\mathrm{H}^{+} \leftrightarrow \equiv \mathrm{S}-\mathrm{OH}_{2}{ }^{+} \\
& \equiv \mathrm{S}-\mathrm{OH}+\mathrm{OH}^{-} \leftrightarrow \equiv \mathrm{S}-\mathrm{O}^{-}\left(\mathrm{H}_{2} \mathrm{O}\right)
\end{aligned}
$$

2. Реакции связывания металлов:

$\equiv \mathrm{S}-\mathrm{OH}+\mathrm{M}^{\mathrm{Z}+} \leftrightarrow \equiv \mathrm{S}-\mathrm{OM}^{(\mathrm{Z}-1)^{+}+} \mathrm{H}^{+}$

$2 \equiv \mathrm{S}-\mathrm{OH}+\mathrm{M}^{\mathrm{Z}} \leftrightarrow \equiv(\mathrm{S}-\mathrm{O})_{2} \mathrm{M}^{(\mathrm{Z}-2)^{+}}+2 \mathrm{H}^{+}$ $\equiv \mathrm{S}-\mathrm{OH}+\mathrm{M}^{\mathrm{Z}+}+\mathrm{H}_{2} \mathrm{O} \leftrightarrow \equiv \mathrm{S}-\mathrm{OMOH}^{(\mathrm{Z}-2)+}+2 \mathrm{H}^{+}$

3. Реакции лигандного обмена: $\equiv \mathrm{S}-\mathrm{OH}+\mathrm{L}^{-} \leftrightarrow \equiv \mathrm{S}-\mathrm{L}+\mathrm{OH}^{-}$ $2 \equiv \mathrm{S}-\mathrm{OH}+\mathrm{L}^{-} \leftrightarrow \equiv \mathrm{S}_{2}-\mathrm{L}^{+}+2 \mathrm{OH}^{-}$

4. Реакции образования тройных комплексов с участием металла и лиганда:

$$
\begin{aligned}
& \equiv \mathrm{S}-\mathrm{OH}+\mathrm{L}^{-}+\mathrm{M}^{\mathrm{Z}+} \leftrightarrow \equiv \mathrm{S}-\mathrm{L}-\mathrm{M}^{\mathrm{Z}+}+\mathrm{OH}^{-} \\
& \equiv \mathrm{S}-\mathrm{OH}+\mathrm{L}^{-}+\mathrm{M}^{\mathrm{Z}+} \leftrightarrow \equiv \mathrm{S}-\mathrm{OM}-\mathrm{L}^{(\mathrm{Z}-2)+}+\mathrm{H}^{+}
\end{aligned}
$$

Из приведенных схем видно, что образование поверхностных комплексов приводит к изменению заряда поверхности и значения $\mathrm{pH}$ среды.

Поверхность твердых частиц имеет заряд, вызывающий взаимодействие ионов; в результате на границе раздела возникает электрический потенциал, формирующий двойной электрический слой (ДЭС). Существует несколько моделей строения ДЭС. Наиболее простая была предложена Гельмгольцем [23]. Согласно ей поверхность частицы имеет равно распределенный отрицательный либо положительный заряд, который полностью компенсируется противоположно заряженными ионами, при этом ионы расположены в плоскостях параллельных друг другу. Модель Гюи-Чапмена характеризует границу раздела между твердой частицей и раствором как плоскую поверхность с равномерно распределенным отрицательным или положительным зарядом, но в отличие от модели Гельмгольдца, на противоположно заряженные ионы воздействуют противоположно направленные силы электростатического притяжения и диффузии. В результате чего формируется диффузный слой, в котором присутствуют и противоположно заряженные ионы, и ионы того же заряда, что и у потенциалопределяющих ионов. Подход Гельмгольца и Гюи-Чапмена объединила модель Штерна, которая описывает строение поверхности раздела коллоидной частицы и окружающего раствора. Согласно модели, на поверхности потенциалопределяющих ионов расположен слой плотно упакованных противоионов с постоянной концентрацией, а далее следует диффузный слой.

\section{Адсорбция и сорбция}

Адсорбция - это процесс накопления (аккумуляции) веществ на границах раздела фаз и ее отличие от осаждения заключается в том, что в процессе осажде- 
ния формируется трехмерная молекулярная структура. Для адсорбции характерны следующие взаимодействия: химические, электростатические, физические $[24,25]$. Для специфической адсорбции характерно участие ковалентных и координационных связей, а процесс протекает в плотной части двойного электрического слоя. Координационные и ковалентные связи действуют на коротких промежутках и приводят к образованию внутрисферных комплексов. Для осуществления неспецифической адсорбции необходимы кулоновские силы, которые способны воздействовать на большие расстояния, что приводит к формированию внешнесферных комплексов в диффузном слое поверхности частиц. При адсорбции неионных неполярных соединений, энергия водородной связи молекул воды оказывается выше энергии связи между молекулами воды и неполярных соединений, что приводит к формированию гидрофобных взаимодействий. Данные взаимодействия осуществляются относительно слабыми и краткосрочными силами Ван дер Ваальса.

Наиболее подробно изучены адсорбционные процессы, происходящие на границе раздела твердая фаза - почвенный раствор и представлены в следующих работах [10, 16-19, 21, 23]. Основной проблемой, при исследовании адсорбции является то, что почва - это поликомпонентная и полидисперсная система, что приводит к энергетической и стерической гетерогенности сорбционных центров на поверхности твердых частиц. Для решения этой проблемы существует два подхода - механический и полуэмпирический [21, 23].

Адсорбционные явления почв можно графически отображать в изотермах адсорбции, представляющих собой графическую зависимость количеств адсорбированных веществ от их равновесной концентрации. Джайлс выделил четыре типа изотерм адсорбции [26, 27].
S-форма изотермы прослеживается при адсорбции катионов $\mathrm{Cu}^{2+}$ тяжелосуглинистой почвой, в присутствии органических лигандов. Кривая имеет малый наклон при незначительных концентрациях, а по мере увеличения равновесной концентрации, наклон возрастает.

L-форма изотермы наблюдается при поглощении фосфатов супесчаной почвой. Кривая экспериментально подтверждает высокое сродство с поверхностью адсорбента при низких концентрациях адсорбата.

Н-форма изотермы характерна при адсорбции $\mathrm{Cd}^{2+}$ суглинистой каолинитовой почвой. Изотерма представляет собой частный случай L-формы, но кривая имеет более крутое начало из-за высокого сродства адсорбата к поверхности адсорбента.

С-форма изотермы представляет собой прямую линию, такую форму имеют адсорбции неионных и гидрофобных соединений, например адсорбция инсектицида $\left(\mathrm{C}_{10} \mathrm{H}_{14} \mathrm{NO}_{5} \mathrm{PS}\right)$ глинистой почвой.

\section{Катионный обмен}

Катионный обмен представляет собой частный случай процесса адсорбции, так как процесс всегда сопровождается концентрацией катиона на границе раздела фаз. Общепринятым является то, что ППК является носителем катионообменной способности почв. Почвенный поглощающий комплекс представлен совокупностью компонентов твердой фазы почвы имеющих минеральное, органическое и органоминеральное происхождение, и которые характеризуются ионообменной способностью. Наибольшая способность к обмену и поглощению катионов приурочена к илистой фракции почв (частиц $<0.001$ мм). Обменными катионами (поглощенными катионами) называются катионы, входящие в состав ППК, способные замещаться катионами другого рода во время взаимодействия с нейтральными растворами солей.

Важной характеристикой ППК является емкость катионного обмена (ЕКО), 
которая определяется гранулометрическим составом почв и строением веществ, входящих в состав ППК. На ЕКО влияет число отрицательных зарядов, которые приходятся на единицу массы (поверхности ППК). Компенсирующее действие отрицательного заряда, является важным свойством обменных катионов, приводящее к электронейтральности каждой частицы ППК. Кроме того, большой емкостью обладают гумусовые вещества.

Для катионного обмена характерна селективность. Так реакция обмена ППК $\mathrm{Ca}^{2+}+\mathrm{Mg}^{2+} \leftrightarrow \Pi \Pi К \mathrm{Mg}^{2+}+\mathrm{Ca}^{2+}$ демонстрирует количественное соотношение двух обменных катионов в ППК. Их количественное отношение не равно отношению их активностей (концентраций) в равновесном растворе, что выражается следующим неравенством:

$$
\frac{\left[\mathrm{Ca}_{\Pi}^{2+}\right]}{\left[\mathrm{Mg}_{\Pi}^{2+}\right]} \neq \frac{a_{\mathrm{Ca}^{2+}}}{a_{\mathrm{Mg}^{2+}}},
$$

где П- катионы ППК; $a_{\mathrm{Ca}^{2+}}, a_{\mathrm{Mg}^{2+}}-$ активность $\mathrm{Ca}^{2+}$ и $\mathrm{Mg}^{2+}$ в равновесном растворе.

Если активность катионов одинакова, то почвы проявляют селективность в отношении поглощения тех или иных катионов, что математически выражается следующим уравнением:

$$
\frac{\left[\mathrm{Ca}_{\Pi}^{2+}\right]}{\left[\mathrm{Mg}_{\Pi}^{2+}\right]}=K \frac{a_{\mathrm{Ca}^{2+}}}{a_{\mathrm{Mg}^{2+}}},
$$

где К - коэффициент селективности, характеризующий распределение катионов между почвенным раствором и твердой частью почвы (ППК). В обобщенной форме коэффициент селективности выражается следующим образом:

$$
K=\frac{\left[M_{1}\right] a_{M_{2}}}{\left[M_{2}\right] a_{M_{1}}},
$$

где $\mathrm{M}_{1}$ и $\mathrm{M}_{2}$ - катионы 1-го и 2-го рода.

Избирательность поглощения определяется свойствами катионов, а также химическими особенностями компонентов, входящих в ППК. Основное правило селективности звучит следующим образом: в первую очередь связываются катионы с большим зарядом, а в случае равных зарядов - катионы с большей атомной массой. Эта закономерность описывается рядами катионов, расположение которых соответствует порядку возрастания степени их поглощения почвой:

$$
\begin{gathered}
\mathrm{Li}^{+}<\mathrm{Na}^{+}<\mathrm{NH}_{4}^{+}<\mathrm{K}^{+}<\mathrm{Rb}^{+}<\mathrm{Cs}^{+}<\mathrm{H}^{+} ; \\
\mathrm{Mg}^{2+}<\mathrm{Ca}^{2+}<\mathrm{Ba}^{2+} ;
\end{gathered}
$$$$
\mathrm{AI}^{3+}<\mathrm{Fe}^{3+} \text {. }
$$

В то же время специфика ППК может изменить порядок расположения катионов в ряду поглощения, например:

Монтмориллонит

$\mathrm{Li}^{+}<\mathrm{Na}^{+}<\mathrm{K}^{+}<\mathrm{H}^{+}<\mathrm{Rb}^{+}<\mathrm{Mg}^{2+}<\mathrm{Ca}^{2+}=\mathrm{Sr}^{2+}<\mathrm{Ba}^{2+}$ Каолинит

$\mathrm{Li}^{+}<\mathrm{Na}^{+}<\mathrm{H}^{+}<\mathrm{K}^{+}<\mathrm{Rb}^{+}<\mathrm{Mg}^{2+}<\mathrm{Ca}^{2+}=\mathrm{Sr}^{2+}=\mathrm{Ba}^{2+}$ Мусковит

$\mathrm{Li}^{+}<\mathrm{Na}^{+}<\mathrm{Mg}^{2+}<\mathrm{Ca}^{2+}<\mathrm{Sr}^{2+}<\mathrm{Rb}^{+}<\mathrm{Cs}^{+}<\mathrm{K}^{+}<\mathrm{Ba}^{2+}$.

Селективность поглощения определяется характером адсорбционных центров и ионными радиусами катионов. Взаимодействие ППК и катионов почвенного раствора чаще всего рассматривается с точки зрения электростатических позиций. Согласно закону Кулона силы взаимодействия нарастают с увеличением заряда катионов и уменьшением их радиусов. Данное правило объясняет приоритет поглощения катионов двух- и трехзарядных. Кроме того, ионы, находящиеся в почвенном растворе гидратированы, и при прочих равных условиях, преимущество получают катионы с менее гидратированной оболочкой.

Активными центрами органической составляющей почвенного поглощающего комплекса являются кислые функциональные группы - карбоксильные и фенольные. В данном случае селективность обмена зависит от прочности связи функциональных групп, а также их расположением в молекуле. Например, в ортоположении они способны образовывать прочные малоподвижные соединения с двух- и трехвалентными катионами. Прочностью связи характеризуются взаимодействия катионов с двумя группами $\mathrm{COOH} \mathrm{расположенными} \mathrm{рядом} \mathrm{незави-}$ симо от их принадлежности к циклическим или алифатическим структурам. 
При увеличении степени окисленности органического вещества ППК и росте констант диссоциации происходит преимущественное поглощение поливалентных катионов.

Высокая скорость обмена характерна, если катионы расположены на поверхностях и сколах частиц ППК (дефекты кристаллической решетки, разрывы связи и т.д.) удерживающиеся только остаточными силами. Быстрый обмен катионов осуществляется функциональными группами, расположенными с внешней стороны поверхности гумусовых веществ. Влажность способствует увеличению скорости обмена катионов. Замедление реакций происходит при взаимодействии катионов межпакетных промежутков глинистых минералов, а также вытесняющим компонентом являются труднорастворимые соли твердой фазы почв.

Согласно законам ионообменной сорбции выделяют 5 стадий реакции обмена, протекающих последовательно между катионами ППК и почвенным раствором: перемещение вытесняющего иона из объема раствора к поверхности ППК; перемещение вытесняющего иона внутри твердой фазы ППК к точке обмена; химическая реакция обмена катионов; перемещение вытесненного иона внутри твердой фазы от точки обмена к поверхности ППК; перемещение вытесненного иона от поверхности ППК в раствор.

Из всех вышеперечисленных стадий определяющей скорость обмена катионов будет та, которая протекает наиболее медленно. Чаще всего это перемещение ионов к точке обмена внутри твердой фазы (внутренняя диффузия), реже, - с внешней диффузией ионов к поверхности ППК. В целом, внутренняя диффузия определяется влажностью, особенностями строения порового пространства, зарядом поверхности твердых частиц, химическими и кристаллохимическими особенностями твердых фаз почвы.
В сельскохозяйственном производстве с целью улучшения почвенного плодородия существует большой комплекс мероприятий по регулированию состава обменных катионов, наиболее распространенными из которых являются известкование и гипсование почв. Косвенное влияние на состав обменных катионов почв способно оказывать орошение, осушение, а также внесение минеральных удобрений. Так внесение минеральных удобрений без известкования приводит к увеличению кислотности почвы. Орошение степных почв сильно минерализованными водами приводит к их осолонцеванию. С целью прогнозирования вероятности вхождения $\mathrm{Na}^{+}$в ППК почвы при ее орошении минерализованными водами, используют показатель адсорбируемости натрия или натриевое адсорбционное отношение SAR. Этот показатель рассчитывают по результатам определения концентрации катионов в воде, используемой для орошения:

$$
S A R=\frac{\left[\mathrm{Na}^{+}\right]}{\sqrt{\frac{\left[\mathrm{Ca}^{2+}\right]+\left[\mathrm{Mg}^{2+}\right]}{2}}}=\frac{1,14\left[\mathrm{Na}^{+}\right]}{\sqrt{\left[\mathrm{Ca}^{2+}\right]+\left[\mathrm{Mg}^{2+}\right]}},
$$

где квадратные скобки - концентрация соответствующих катионов в воде (в мг-экв/дм $\left.{ }^{3}\right)$. Показатель позволяет оценить качество ирригационной воды и ее пригодность для орошения без риска осолонцевания почв. Чтобы улучшить свойства почв с высоким содержанием обменного $\mathrm{Na}$ чаще всего используют гипсование. Метод основан на реакции вытеснения из ППК обменного $\mathrm{Na}^{+}$катионами $\mathrm{Ca}^{2+}$ гипса:

$$
\begin{aligned}
& \Pi \mathrm{Na}_{2}+\mathrm{CaSO}_{4} \leftrightarrow \Pi \mathrm{INa}_{2}+\mathrm{Ca}^{2+}+\mathrm{SO}_{4}{ }^{2-} \\
& \leftrightarrow \Pi \mathrm{Ca}+2 \mathrm{Na}^{+}+\mathrm{SO}_{4}{ }^{2-} \text {. }
\end{aligned}
$$

Гипс $\mathrm{CaSO}_{4} \cdot 2 \mathrm{H}_{2} \mathrm{O}$ сравнительно хорошо растворим. В результате взаимодействия образуется соль, способствующая коагуляции почвенных коллоидов и в дальнейшем легко вымывается из почвенного профиля рядом промывок.

Целью любых мелиоративных приемов является оптимизация состава обменных катионов, в результате которой 
происходит не только улучшение условий развития сельскохозяйственных растений, но и повышение стабильности почвы, ее устойчивости к влиянию различных неблагоприятных факторов.

\section{Современное состояние проблемы}

В настоящее время достаточно много исследований проводится с использованием моделирования как компьютерного, так и экспериментально-лабораторного. В работе [28] приводятся результаты экспериментальных данных полученных лабораторным путем в результате взаимодействия гуминовых препаратов и микробиты, приводится оценка дескриптивной (описательной) способности двух интегральных биотических индексов, полученных на основе эксперимента. Для моделирования опыта использовали образцы субстратов в виде песка, каолина и торфа, которые загрязняли медью. В работе [29] приводятся расчеты кинетических и термодинамических параметров сорбции катионов $\mathrm{Zn}$ и $\mathrm{Cu}$ на ГК. Достаточно много исследований посвящено изучению органо-минеральным взаимодействиям, которые непрерывно протекают в почвах. Значение данных взаимодействий в том, что они демонстрируют механизмы образования почвенной структуры, с их помощью можно регулировать дисперсность, они влияют на физико-химические свойства сформированных агрегатов [30-32]. Артемьева и Кириллова исследовали [30] роль органоминеральных компонентов в структурообразовании, а также гумусообразовании ведущих типов почв центра Русской равнины. Приводятся основные методы гранулометрического фракционирования и их модификация.

Подвижность основных компонентов органического вещества почв находится в динамике и определяется образованием минералорганических соединений на поверхности почвенных агрегатов. На нее оказывают влияние поверхность глини- стых минералов, их химическая и энергетическая неоднородность, а также аморфные соединения Al, Fe и Si. Перечисленные процессы влияют на поглотительную и миграционную способности элементов по профилю почв [33-40]. Особого внимания заслуживают интересные взгляды об организации почв, так различают матричную, фрактальную [31, 41, 42], кластерную [24, 33-36, 43]. Федотов [31] в своих исследованиях доказывает присутствие в почвах органоминерального геля в виде единого каркаса. Гелиевые структуры образуют в твердой фазе почвы единый с почвенным раствором коллоидногелевый каркас или матрицу. Перспективным в характеристике структурного состояния почв и кластерных свойств почвенной поверхности с адсорбированными на ней полиэлектролитами является использование фрактальной размерности [36]. Такой подход используется для характеристики поверхностных свойств почв, почвенных минералов и коллоидных структур. В настоящее время преследуются цели изучения коагуляционной устойчивости почвенных суспензий при воздействии на них адсорбированной почвами гуминовой кислоты [44-46].

\section{Заключение}

Исследованию сорбционных свойств и процессов почв, их динамике, изучению поглотительной способности посвящено множество трудов не только в России, но и в мировой науке. На такую популярность оказывает большое влияние резко увеличившаяся техногенная нагрузка на почвы, которая чаще всего приводит к их загрязнению ТМ, мышьяком, радионуклидами, нефтепродуктами и другими компонентами кислотной и основной природы. Кроме того, интерес к этой научной тематике связан с переходом экономически развитых стран к интенсивным системам ведения сельского хозяйства. Данный способ земледелия позволяет получить высокие урожайности сельскохозяйственных культур, однако 
это требует внесения высоких доз удобрений, мелиорантов, стимуляторов роста и пестицидов. Прогнозирование процессов поступления, миграции, трансформации и аккумуляции загрязняющих веществ в почвах, их поступление в сопредельные среды, а также растительные и живые организмы осуществляется при помощи полной информации о сорбционных свойствах почв. Поэтому углубленное изучение вопросов природы сорбционных центров, приуроченных к химически активным функциональным группам органического вещества почвы, а также глинистых минералов является важным направлением современной химии почв. В настоящее время при изучении сорбционных свойствах почв исследователи сталкиваются с рядом вопросов и про- блем, которые необходимо решить в будущем. Гетерогенность состава почв и недостаточность сведений о строении молекул гуминовых и фульвокислот не дают возможности контролировать процессы аккумуляции многих загрязняющих веществ в почвах. В то время как решение данных проблем дало бы возможность контролировать экологическое состояние не только почв, но и биосферы в целом. Взаимодействие органических и минеральных компонентов почв, а также элементов поступающих из вне, определяется природой и характером поверхности минералов, величиной $\mathrm{pH}$ и содержанием воды в почве, а также рядом других факторов, которые нуждаются в детальном исследовании при обязательном комплексном подходе.

\title{
Sorption processes in soils. Study issues and the current state of the problem
}

\author{
(C) 2021 Gorbunova N.S., Gromovik A.I., Cherepukhina I.V., Terentyeva Yu.Yu. \\ Voronezh State University, Voronezh, Russian Federation
}

Interest in the study of the sorption capacity of soils, exchangeable cations, sorption and adsorption, and the study of interactions between organic and mineral components in the modern literature is associated not only with the elucidation of the mechanisms of formation of humic substances of a specific and nonspecific nature, but also with the formation of a soil-absorbing complex. The importance of the issue is associated with the current ecological state of the soils and biosphere due to the increasing anthropogenic pressures. Goal: to identify the main trends in the formation, development, and current state of the problem of studying the sorption properties of soils and processes associated with them.

Tasks: study of the origin, formation and development of science about the absorption capacity of soils, soil-absorbing complex, sorption processes occurring in the soil, exchangeable and absorbed cations; the kinetics of the process; analysis of modern literature on the interaction of soil-absorbing complex, clay minerals, organo-mineral compounds with substances coming from outside; the matrix, fractal, and cluster organization of soils.

Due to the modern anthropogenic load and the increasing intensification of agricultural production, there is an increased ploughing of land, leading to a shift in the equilibrium of the colloidal system towards coagulation. However, according to the latest data obtained, arable soils withdrawn from agricultural use are capable of autoregeneration, which is manifested primarily in the restoration of their colloidal system to its original state. Equilibrium shifts towards peptization. Modern concepts of soils as a colloidal-gel matrix allowed considering soils as systems in which soil properties are determined by the state and properties of soil gels formed as a result of the interaction of humic substances and mineral nanoparticles. Mineral-organic components formed on the surface of soil mineral compounds and its aggregates through the adsorption of molecules of organic compounds lead to a strong transformation of the surface. The result of these processes is the specificity and selectivity of the surface in the absorption of a number of substances.

Keywords: soil-absorbing complex, absorption capacity of soils, sorption properties of soils, adsorption and sorption, cation exchange. 


\section{Список литературы / References}

1. Gedrojc K.K. Uchenie o poglotitel'noj sposobnosti pochv. Pochvennye kolloidy i poglotitel'naja sposobnost' pochv., M., Sel'hozgiz, $1955,559 \mathrm{p}$.

2. Mattson S.Je. Pochvennye kolloidy, M., Sel'hozgiz, 1934, 123 p.

3. Gapon E.N., Pochvovedenie, 1934, No 2, pp. 190-201.

4. Nikol'skij B.P., Pochvovedenie, 1934, No 2, pp. 180-190.

5. Antipov-Karataev I.N., Kader G.M., Kolloidnyj zhurnal, 1947, Vol. 9, No 5, pp. 315-324.

6. Chernov V.A., O prirode pochvennoj kislotnosti, M., Leningrad, AN SSSR, 1947, 185 p.

7. Remezov N.P. Emkost' pogloshhenija i sostav obmennyh kationov $\mathrm{v}$ glavnejshih tipah pochv. Khimija i genezis pochv, M., Nauka, 1989, $579 \mathrm{p}$.

8. Aleksandrova L.N., Pochvovedenie, M., Kolos, 1982, $495 \mathrm{p}$.

9. Kononova M.M. Organicheskoe veshhestvo pochvy, ego priroda, svojstva i metody izuchenija. M., nauka, 1963, $313 \mathrm{~s}$.

10. Orlov D.S. Khimija pochv, M., MGU, 1992, $400 \mathrm{p}$.

11. Tjurin I.V. Organicheskoe veshhestvo pochvy i ego rol' v plodorodii, M., Nauka, 1965, 320 p.

12. Stevenson F.J. Humus Chemistry, Genesis, Composition, Reaction, New York, John Wiley, 1994, $444 \mathrm{p}$.

13. Gorbunov N.I., Mineralogija i fizicheskaja himija pochv, M., AN SSSR, 1978, 293 p.

14. Gradusov B.P., Mineraly so smeshanoslojnoj strukturoj v pochvah, M., Nauka, $1976,128 \mathrm{p}$.

15. Chizhikova N.P0., Preobrazovanie mineralogicheskogo sostava pochv $\mathrm{v}$ protsesse agrogeneza, Avtoreferat, M., 1991, 48 p.

16. Sposito G., The Chemistry of Soils, New York, Oxford, Oxford University Press, 1989, $279 \mathrm{p}$.

17. Sposito G., The Surface Chemistry of Soils. New York, Clarendon Press Oxford, Oxford University Press, 1984, 228 p.

18. Stumm W. Chemistry of the Solid-Water Interface. New York, Chichester, Brisbane, Toronto, Singapore John Wiley \& Sons, Inc., 1992, $428 \mathrm{p}$.

19. Stumm W., Morgan J.J., Aquatic Chemistry. New York, John Wiley \& Sons, Inc., 1981, $796 \mathrm{p}$.
20. Sparks D., Kinetics of Soil Chemical Processes, San Diego, Academic Press, 1989, 210 p.

21. Sparks D. L. Soil Physical Chemistry. Boston, London, New York, Washington, D.C., CRC Press. Boca Raton, 1999, 410 p.

22. Mironenko E.V., Pachepskij Ja.A., Ponizovskij A.A., ONTI NCBI AN SSSR, 1981, $52 \mathrm{p}$.

23. Essington M.E. Soil and Water Chemistry. London, New York, Washington D.C., CRC Press. Boca Raton, 2004, 534 p.

24. Pinskij D.L., Kurochkina G.N. Jevoljucija uchenij o fiziko-khimicheskoj poglotitel'noj sposobnosti pochv. Pochvennye processy i prostranstvenno-vremennaja organizacija pochv. Moskva, Nauka, 2006, p. 295-311.

25. Israelashvili J.N., Intermolecular and Surface Forces, London, Academic Press, 1985, 435 p.

26. Dzhajls CH., Ingram B., Kljuni Dzh., Liklema Ja. Adsorbcija iz rastvorov na poverhnosti tverdyh tel, M., Mir, 1987, 287 p.

27. Giles C.H., Smith D., Huitson A., Colloid Interface Science, 1974, Vol. 47, pp. 755-765.

28. Jakimenko O.S., Terehova V.A., Pukal'chik M.A., Gorlenko M.V. et al., Pochvovedenie, 2019, No 7, pp. 781-792.

29. Lodygin E.D., Pochvovedenie, 2019, No 7, pp. 817-826.

30. Artem'eva Z.S., Kirillova N.P., Bjul. Pochv.in-ta im. V.V. Dokuchaeva, 2017, Vyp. 90, pp. 73-95.

31. Fedotov G.N., Shalaev V.S. Osnovy nanostrukturnoj organizacii pochv. M., 2012, $512 \mathrm{p}$.

32. Artemyeva Z., Zigova A., Kirillova N., Št’astný M. et al., Archivesof Agronomy and Soil Science, 2017, Vol. 63, pp. 1-14.

33. Kurochkina G.N., Pinskij D.L., Fizikohimija poverhnosti $i$ zashhita materialov, 2016, Vol. 52, No 3, pp. 1-6.

34. Kurochkina G.N., Pinskij D.L., Fedotov G.N., Hajnos M. et al., Pochvovedenie, 2013, No 8, pp. 993-1004.

35. Kurochkina G.N., Pinskij D.L., Hajnos M., Sokolovska S. et al., Pochvovedenie, 2014, No 7, pp. 842-850.

36. Kurochkina G.N., Pinskij D.L., Hajnos M., Sokolovska S. et al., Agrokhimija, 2013, No 10, pp. 58-66.

37. Alekseev A., Alekseeva T., Kalinin P., Hajnos M., Soil Tillage Res., 2018, Vol. 180, pp. 38-47. 
38. Balcke G.U., Kulikova N.A., Hesse S., Kopinke F.D. et al., Soil Science, 2002, Vol. 66, pp. 1805-1812.

39. Chenu C., Plante A.F., Soil Science, 2006, Vol. 57, pp. 596-607.

40. Chotzen R.A., Polubesova T., Chefetz B., Mishael G.Y., Clay and Clay Minerals, 2016, Vol. 64, pp. 628-638.

41. Zubkova T.A., Karpachevskij L.O. Matrichnaja organizacija pochv, M., Rusaki, 2001, 295 p.

Горбунова Надежда Сергеевна - к.б.н., доцент кафедры почвоведения и управления земельных ресурсов Воронежского государственного университета, Воронеж

Громовик Аркадий Игоревич - к.б.н., доцент кафедры почвоведения и управления земельных ресурсов Воронежского государственного университета, Воронеж

Черепухина Ирина Вячеславовна - к.б.н., старший преподаватель кафедры почвоведения и управления земельных ресурсов Воронежского государственного университета, Воронеж

Терентьева Юлия Юрьевна - ассистент кафедры почвоведения и управления земельных ресурсов Воронежского государственного университета, Воронеж
42. Sokolowska Z., Sokolowski S., Geoderma, 1999, Vol. 88, pp. 233-249.

43 Pinskij D.L., Ionoobmennye processy v pochvah, Pushhino, ONTI PNC RAN, 1997, $165 \mathrm{p}$.

44. Kurochkina G.N., Pochvovedenie, 2020, No 1, pp. 69-80.

45. Kurochkina G.N., Pochvovedenie, 2017, No 8, pp. 954-964.

46. Kurochkina G.N., Fizikokhimija poverhnosti i zashhita materialov, 2019, Vol. 55, No 2, pp. 158-169.

Gorbunova Nadezhda S. - Ph.D., Associate Professor of the Department of Soil Science and Land Resources Management, Voronezh State University, Voronezh, e-mail: vilian@list.ru

Gromovik Arkady I. - Ph.D., Associate Professor of the Department of Soil Science and Land Resources Management, Voronezh State University, Voronezh, e-mail: agrom.ps@mail.ru

Cherepukhina Irina V. - Ph.D., Senior Lecturer, Department of Soil Science and Land Resources Management, Voronezh State University, Voronezh, e-mail: irenius@list.ru

Terentyeva Yulia Yu. - Assistant of the Department of Soil Science and Land Resources Management, Voronezh State University, Voronezh, email: khatunceva yliann@list.ru 